\title{
Review: Warfare with odours
}

Insect-plant Interactions and Induced Plant Defence (Novartis Foundation Symposium 223). Editors: Derek J. Chadwick (organizer) and Jamie A. Goode (1999). John Wiley \& Sons Ltd, Chichester, England. $281 \mathrm{pp}$.

Plants don't like to be eaten and all of us know that therefore they use a number of tricks to minimise losses inflicted on them by herbivores and kin. Spikes, spines, needles, spicules, thorns and barbs as well as toxic substances in leaves, stems and fruits are some of the better known measures with which plants increase their unpalatability. But how many of us would have imagined that some plants can warn others with wafts of secret perfumes when attacked by insects or, more cunning still, emit odours to attract the enemies of those insects that harm the plant? If you are an entomologist, ecologist, molecular biologist or plant physiologist not familiar with semiochemicals and would like to learn more about the way plants use volatile substances as odour signals in their battle against insects, then this book is for you. Although not a textbook and certainly not an easy book to read (no photographs, few illustrations), this volume of 281 pages of $15 \times 23 \mathrm{~cm}$ by the Novartis Foundation (known till 1997 as the Ciba Foundation) covers a lot of ground and is based on a Symposium that took place in London in 1998. It lists 27 participants from at least 8 countries.

In the first three chapters the scene is set for the conspiracy between plants and carnivores in tri-trophic interactions (L.E.M. Vet). Evidence is provided that plants not only send signals to insects, telling them whether or not the plant from which the chemical originates is a suitable host, but that plants also signal between themselves and in addition emit volatiles that attract enemies of their enemies. Sesquiterpenes and indoles are particularly attractive to the maize caterpillar Spodoptera parasitoid Cotesia margiventris, and once parasitized, caterpillars (even if they do not die immediately) do consume less plant tissue than unparasitized individuals (T.C.J. Turlings and M.E. Fritzsche). A discussion with questions and answers by experts follows each chapter, while more general discussions, inserted between chapters 3 and 4 and also chapters 10 and 11 as well as at the end of the book integrate and summarise the findings that were presented between the preceding pages. The discussions are excellent and one can extract much useful additional information from them (and especially the usually quite extensive answers). Some examples of dozens of interesting questions: Can fungal infections induce the emission of plant volatiles? Do undamaged plants also release volatiles or how do herbivorous insects detect host plants in the first place? What about hyperparasitoids? Why and how do herbivorous insects allow the plant to respond to them? Are mi- croorganisms in the spit of insects producing significant signals or is it something from the spit itself? Is learning involved? Do volatiles differ in plants that have flowered?

For more than 100 plant species in 34 families specific herbivore-induced direct defences are now known. Indirect defences have been shown to exist in more than 20 plant species, covering 13 families, and specificity (= difference between herbivory and mechanical wounds) stems from the oral secretions of the herbivore (M. Dicke). How the insects extract the information content from the volatile blend can be studied through behavioural experiments or electrophysiological tests (L.J. Wadhams et al.). The chapter by I.T. Baldwin deals with direct and indirect defences in Nicotiana plants and contains two illustrations, which are very useful to understand the complexities of the system. Chapters by J.H. Tumlinson et al., W. Boland et al., and A.Gierl \& M. Frey provide chemical formulae of the major volatile compounds (indoles, terpenoids, etc.), explain aspects of the biosynthesis of the semiochemicals in plants (including the topical lipoxygenase pathway to produce jasmonic acid: key regulator for the synthesis and release of plant volatiles) and examine the hydroxamic acid pathway with a view on toxic secondary metabolites that function as natural pesticides. All of this is at the cutting edge of research, fascinating and exciting to read. A perspective of the biotechnological applications of terpenoid synthases for the genetic engineering of agricultural crops is presented by J. Bohlmann \& R. Croteau in their chapter on the molecular genetics of terpenoid defences in conifers (Abies grandis). In the general discussion to these chapters one learns that herbivores make volicitin (to which plants respond with volatiles) from the linolenic acid obtained from the plant. Why they do this may be related to the fact that there are no bile salts in the insect gut/digestive system (only fatty acid-based detergents).

The last 7 chapters examine some specific situations, for example that in transgenic tobacco a reduction of phenylpropanoid reduces the systemic acquired resistance (SAR) to tobacco mosaic virus, while increasing phenylpropanoid enhances SAR (G.W. Felton et al.). Phytoalexins, like avenalumin and others (chemical formulae are given, but in the index these chemicals are not listed) in plant protection, are the topic of R. Hammerschmidt \& E.K. Dann's chapter, while E.W. Weiler et al. provide first insights into the processes and the use of cloning of several enzymes in particular of the octadeca- 
noid pathway. Excellent illustrations accompany this otherwise very specialized chapter. Commercial development possibilities and likely future uses of plant signals in agricultural and industrial crops are discussed in chapters by R.A. Dietrich et al., and R. Karbon. A review by T. Mitchell-Olds of functional genomics approaches for the identification of insect resistance genes in Arabidopsis (and to a minor extent Brassica) and a critical assessment by J.A. Pickett et al. of possible pest control methods and techniques to investigate insect interactions with phyto-pheromones are the final two chapters of the book. A terminal discussion of about three pages wraps up the symposium.

I found this an extremely stimulating book, written, admittedly, not for the general entomologist or natural historian, but for researchers specializing in airborne plant chemicals functioning as signals between plants and insects. The cited literature, as far as I can tell, is thorough and totally current. The book really has few drawbacks, the singularly unattractive cover of two roughly-drawn human faces with perhaps indications of odour plumes between their noses being the biggest one by far. The price of $£ 75.00$ for the book is also not exactly attractive. A few omissions or inaccuracies in the index are present (caryophyllene is in the subject index, but the page on which its chemical formula appears is not and the same goes for volicitin). Furthermore ignored are whether burning, drought, UV-radiation, etc. induce the synthesis and emission of semiochemicals via the fatty acid/lipoxygenase pathway, for the plant injury response does appear to exhibit similarities with cell damage in human and animal tissues ( $c f$. Hölzel and Spiteller 1995). For someone who has held an interest in plant galls for decades (although reflected only through one early publication: Meyer-Rochow 1970), I was surprised to find no mention at all of this form of plant defence (given its widespread occurrence in a variety of plants: Redfern \& Askew 1998) and whether plant galls induce volatiles or emit them themselves. Clearly, the field of research the book deals with is young, exciting, and undoubtedly expanding. One can be anxious to see perhaps a follow-up volume in a few years from now and that may then also contain some observations on plant galls and their volatiles.

Hölzel, C. \& Spiteller, G. 1995: Zellschädigung als Ursache für die Bildung von Hydroperoxiden ungesättigter Fettsäuren. - Naturwissenschaften 82: 452460.

Meyer-Rochow, V. B. 1970: Pemphigus spirothecae: Erzeugerin der Spirallockengalle der Pyramidenpappel. - Math. Naturwiss. Unterr. 23: 292-294

Redfern, M. \& Askew, R.R. 1998: Plant galls (Naturalists' Handbook 17). - Richmond Publ., Slough, England, 99 pp.

V.B. Meyer-Rochow 